\title{
Assessment of job satisfaction and job related stress among pharmacists in the West Bank, Palestine
}

\author{
RESEARCH
}

\section{Jawna Sirhan, Hussein Hallak, and Maher Khdour*}

Faculty of Pharmacy, Al-Quds University, Abu Deis, PO Box 20002, West Bank, Palestine.

\begin{abstract}
A B S T R A C T
Job satisfaction is considered one of the essential factors contributing to a person's motivation, productivity and overall well-being, the present study aimes to assess job satisfaction and job-related stress levels among pharmacists that are currently registered and practicing in Palestine. we report a cross-sectional survey, including measures of satisfaction and stress (Health Professions Stress Inventory) questionnaire. Data were analysed using descriptive statistics, t-tests and one way ANOVAs. The significance level was set at $P<0.05$. Out of 694 questionnaires distributed, 576 were returned; 14 were not completed and excluded from analysis giving a net of 554 (79.8\%) participants. Most of the respondents in the analysis sample were female (58.3\%) working in community pharmacies (73.6\%). The level of job satisfaction was $58.5 \%$, the variables that contributed to the statistically significant, differences in the degree of job satisfaction were the region $(p<0.001)$ and the monthly income $(p<0.001)$. The t-tests and ANOVA analyses revealed that hospital pharmacists were the least likely to respond that job conflicts with family responsibility as a source of stress compared with community pharmacists (3.11 vs 2.14; $p<0.001)$ and least likely scores in the professional recognition domain ( 3.21 vs. $2.79 ; p=0.04$ ), respectively. Other job stressors like excessive work load, lack of promotion opportunities and poor physician pharmacists' relationship have also been reported. Work life of pharmacists should be enhanced in order to improve their motivation and ability, because failure to reduce stress among workers puts both pharmacists and patients at risk.
\end{abstract}

Keywords: Community pharmacists, Hospital pharmacists, Job Satisfaction. Job related-stress, Palestine.

\section{Introduction}

After a job evaluation, one can experience a pleasing emotional response, which is known as job satisfaction, which is reflected in a person's attitude toward their job(Baloch 2009).Job satisfaction is considered one of the essential factors contributing to a person's motivation,

\footnotetext{
* Correspondence:

Faculty of Pharmacy, Al-Quds University, PO Box 20002, Jerusalem, Palestine.

E-mail:mkhdour@pharm.alquds.edu

(c) copy rights 2021: All materials in this article are protected. permission requests should be addressed to Al-Quds University. www. alquds.edu
}

productivity and overall well-being (Sansgiry and Ngo 2003). Evaluation of Pharmacist job satisfaction is of vital importance due to the fact that it reflects stability in the work place since pharmacist commitment to workplace, turnover or consideration to leave the profession are all related to job satisfaction (Desselle and Peirce 2011, Ferguson, Ashcroft et al. 2011). Furthermore, poor job satisfaction of pharmacist may affect job performance, patient care or patient interaction (Saari and Judge 2004, Kreling, Doucette et al. 2006), worst of all it can lead to dispensing errors 
and increased risk of patient harm(Mott, Doucette et al. 2004, Faragher, Cass et al. 2013, Mukattash, Alzoubi et al. 2016). Another factor that may affect pharmacist performance is stress. The job of pharmacist requires a a great deal of responsibility and a heavy workload. Thus, as with numerous health professions, there is an increasing stress level in the pharmacy (Felton 1998, Merrick 2000, Edwards and Burnard 2003, Keil 2004, McNeely 2005, Stafford-Brown and Pakenham 2012). The elevated stress that a pharmacist experiences may be attributed to unreasonable workload expectations, long work hours and poor communication. Previous research suggests that one of the main indicators of workplace stress is interpersonal conflict with co-workers or physicians. In some instances, this may be a reason why pharmacists choose to leave the profession (Herzog 2000, Kälvemark, Höglund et al. 2004, Austin, Gregory et al. 2010). Part of a pharmacist's stress is due to the fact that establishing a relationship of trust and collaboration with physicians is often a challenge(Smith, Ray et al. 2002, Snyder, Zillich et al. 2010). In Palestine, job satisfaction and job stress in the pharmacy profession has not been studied. To date, this study represents the first time that job satisfaction and job-related stress levels have been assessed among pharmacists that are currently registered and practicing in Palestine.

\section{Methods}

Study setting and design

The study was conducted in the West Bank of Palestine between April and October in 2018 and was cross-sectional and questionnaire based. The West Bank is separated into three regions, including the Northern region, the Central region and the Southern region.

\section{Study participants}

The finally target population for this study included all registered Palestinian Pharmaceutical Association (PPA) member pharmacists that were working in different pharmaceutical sectors (community pharmacy,private pharmacy, hospital pharmacy, pharmaceutical company and medical representative) in the West Bank. At the time of the study, there were 4100 PPA registered pharmacists in the West Bank.

\section{Study Sample}

A proportionate stratified random sampling technique was used to achieve the study aims and goals. In this sampling technique, the sample size selected from each stratum is proportionate to the relative size of that stratum in the study population. The sample size was calculated using the Raosoft ${ }^{\circledR}$ sample size calculator. The sample size was 256 pharmacists, which was the minimum recommended number.

\section{Ethical approval}

The Al-Quds University Research Ethics Committee (REC) approved the protocol for this study; Ref No. (39/REC/2018). An explanation of the study rationale was provided and pharmacists were confirmed that the survey would measure job satisfaction, their attitudes and stress. Willingness to participate was a fundamental condition in the study.

\section{Study instrument}

The questionnaire was developed by evaluating the literature and the questionnaires that were utilized in similar studies (McCann, Hughes et al. 2009). The questionnaire consisted of 4 sections. The first section was the sociodemographic data (e.g. age and gender). The second section included four points related to job satisfaction. The third section included a subsection of questions (30 items) that were from the Health Professions Stress Inventory (HPSI), which was established by Wolfgang (Wolfgang 1988). The HPSI questionnaire consists of 4 areas, including patient care responsibility (7 items), job conflicts (8 items), professional recognition (8 items) and professional uncertainty (7 items). For this part, the pharmacists were asked to rate 30 situations using a five-point Likert scale (the responses ranged from $1=$ never stressed to 5 =frequently stressed). The fourth section was optional and was for free text responses 
on other characteristics of job satisfaction and stress, such as physicians' cooperation, sick leave and overtime work. The questionnaire was developed in English language and translated to Arabic by a committee of three Professors, two of them in Pharmacy domain. A statistics professor first performed the content validity, and then, the questionnaire was translated back into English to ensure accuracy of the tool. A pilot questionnaire was first used using 30 pharmacists in order to assess the research tools, with respect to acceptability, applicability, and the period. The stability of the total degree of the stability coefficient was calculated to verify the stability of the tool for the fields of study using the Cronbach Alpha stability equation and the total score (0.896). This resulting value indicated that the tool was consistent with the goals of the study.

\section{Data Analysis}

All the statistical analyses were done using SPSS version 21 (SPSS Inc., Illinois, USA), and $P<0.05$ was considered significant. The statistical processing of the data was performed by extracting the mean and standard deviation of each paragraph of the questionnaire. A t-test and a one-way ANOVA were performed, and the Pearson correlation coefficient was calculated. A least significant differences (LSD) post-hoc test was used to identify the differences between the groups when significant differences were found and when the independent variable was composed of more than one level. The degree of average responses on a four-point scale of $\leq 2.00$ was considered low, 2.01 - 3.00 was considered medium and $\geq 3.01$ was considered high. The degree of average responses on a five-point scale of $\leq 2.33$ was considered low, $2.34-3.67$ was considered medium and $\geq 3.68$ was considered high.

\section{Results}

Of the 694 questionnaires distributed, 576 were returned; 14 were not completed and excluded from analysis giving a net of 554 (79.8\%) participants. Table 1 is a summary of the socio-
Table 1: Participant pharmacists demographic data $(N=554)$

\begin{tabular}{|c|c|c|c|}
\hline Variable & & N & $\%$ \\
\hline \multirow[t]{3}{*}{ Region } & North & 281 & 50.7 \\
\hline & South & 115 & 20.8 \\
\hline & Middle & 158 & 28.5 \\
\hline \multirow[t]{2}{*}{ Gender } & Male & 231 & 41.7 \\
\hline & Female & 323 & 58.3 \\
\hline \multirow[t]{3}{*}{ Age } & From 22-30 years & 321 & 57.9 \\
\hline & From 31-40 tears & 137 & 24.7 \\
\hline & More than 40 years & 96 & 17.3 \\
\hline \multirow[t]{3}{*}{ Marital Status } & Single & 186 & 33.6 \\
\hline & Married & 362 & 65.3 \\
\hline & Widowed /Divorced & 6 & 1.1 \\
\hline \multirow[t]{4}{*}{ Graduation year } & 1990 and before & 31 & 5.6 \\
\hline & $1991-2000$ & 84 & 15.2 \\
\hline & $2001-2010$ & 149 & 26.9 \\
\hline & 2011 and above & 290 & 52.3 \\
\hline \multirow{4}{*}{$\begin{array}{l}\text { P h a r m a c y } \\
\text { License }\end{array}$} & 1990 and before & 27 & 4.9 \\
\hline & $1991-2000$ & 80 & 14.4 \\
\hline & $2001-2010$ & 144 & 26.0 \\
\hline & 2011 and above & 303 & 54.7 \\
\hline \multirow[t]{4}{*}{ Daily Work } & Less than 6 hours & 26 & 4.7 \\
\hline & $6-8$ & 373 & 67.3 \\
\hline & $9-12$ & 121 & 21.8 \\
\hline & More than 12 & 34 & 6.1 \\
\hline \multirow[t]{3}{*}{ Academic Degree } & B. Sc. & 453 & 81.8 \\
\hline & Pharm. D & 61 & 11.0 \\
\hline & Post Bach. Pharm. D & 40 & 7.2 \\
\hline \multirow[t]{4}{*}{ Practical Setting } & Community Pharmacy & 408 & 73.6 \\
\hline & Hospital & 79 & 14.3 \\
\hline & Pharmaceutical Company & 37 & 6.7 \\
\hline & Medical Representative & 30 & 5.4 \\
\hline \multirow[t]{2}{*}{ Position } & Owner of the pharmacy & 172 & 29.8 \\
\hline & employee & 382 & 67.1 \\
\hline \multirow[t]{5}{*}{ Experience } & $<$ a year & 114 & 20.6 \\
\hline & $1-3$ & 165 & 29.8 \\
\hline & $4-6$ & 91 & 16.4 \\
\hline & $7-10$ & 51 & 9.2 \\
\hline & $>10$ years & 133 & 24.0 \\
\hline \multirow[t]{7}{*}{ Monthly income } & $<1000 \mathrm{NIS}$ & 9 & 1.6 \\
\hline & $1000-2000$ & 171 & 30.9 \\
\hline & $2001-3000$ & 158 & 28.5 \\
\hline & $3001-4000$ & 87 & 15.7 \\
\hline & $49001-5000$ & 51 & 9.2 \\
\hline & $5001-6000$ & 36 & 6.5 \\
\hline & $>6000 \mathrm{NIS}$ & 42 & 7.6 \\
\hline \multirow[t]{2}{*}{ Job Status } & Full time job & 372 & 67.1 \\
\hline & Part time job & 182 & 32.9 \\
\hline
\end{tabular}

demographic characteristics of the respondents. Most of the respondents in the analysis sample 
were females (58.3\%) working in community pharmacies (73.6\%), the greatest proportion of the respondents lived in the North (50.7\%). The young pharmacists (22-30 years) who graduated and obtained pharmacy license after 2011 were more than (50\%) of the sample population. According to last the two columns in Table 2, among their daily duties, pharmacists devoted $55 \%$ of their patientassociated activities to medication dispensing, $35 \%$ of their time was for patients consultation and drug use management, while $29 \%$ of their time was dedicated to pharmaceutical care, $28 \%$ to education, and $24 \%$ was for business management and marketing. Amazingly, only 16\% of the time was dedicated to clinical pharmacist services, and 15\% was for disease management. When pharmacists were asked about any plans for leaving the current employment next year; $30 \%$ of the respondents intended to leave work next year, and $34.3 \%$ of them had a possibility to leave their work. The reason for leaving work was $22.2 \%$ due to salary, $21.3 \%$ due to workload and work schedule.

\section{Job satisfaction}

The level of job satisfaction is presented in Table 3, showing that $58.5 \%$ were satisfied and $21.7 \%$ were dissatisfied. A total of $54.6 \%$ of the respondents reported satisfaction with their current job, and 14\% were dissatisfied. As part of the questionnaire, the pharmacists were asked about whether or not they would select pharmacy as a career again if they had a choice, and $33.4 \%$ of the respondents said that they would select the specialty of pharmacy again, while $23 \%$ of them responded that when they leave work, they have a "bad" feeling, because they do not enjoy their job. Job satisfaction and work pressure showed a statistically significant inverse relationship (Pearson $r=-0.112, p<0.01$ ). The variables that contributed to the statistically significant differences in the degree of job satisfaction were

Table 3. Numbers and percentages of the study sample responses at the Level of Job Satisfaction

\begin{tabular}{lcc}
\hline Item & $\mathrm{N}$ & $\%$ \\
\hline Are you satisfied with your job? & & \\
$\quad$ Very Dissatisfied & 51 & 9.2 \\
Dissatisfied & 69 & 12.5 \\
Neither & 110 & 19.9 \\
Satisfied & 200 & 36.1 \\
$\quad$ Very satisfied & 124 & 22.4
\end{tabular}

Are you satisfied with Your present job compared to others

$\begin{array}{lcc}\text { Very Dissatisfied } & 33 & 6.0 \\ \text { Dissatisfied } & 44 & 7.9 \\ \text { Neither } & 119 & 21.5 \\ \text { Satisfied } & 208 & 37.5 \\ \text { Very satisfied } & 150 & 27.1\end{array}$

How often do you leave work with a "bad" feeling, a feeling that you are doing something you do not enjoy

$\begin{array}{lcc}\text { Never } & 69 & 12.5 \\ \text { Rarely } & 215 & 38.8 \\ \text { Sometimes } & 145 & 26.2 \\ \text { Often (most of the time) } & 118 & 21.3 \\ \text { Very Often (all of the time) } & 7 & 1.3\end{array}$

If you could start your career over, would you choose to do pharmacy again?

$\begin{array}{lcc}\text { Definitely No } & 174 & 31.4 \\ \text { Don’t know } & 88 & 15.9 \\ \text { May be } & 107 & 19.3 \\ \text { Definite yes } & 185 & 33.4\end{array}$

Table 2. Pharmacists' work activities and work environment (n \%)

\begin{tabular}{|c|c|c|c|c|c|c|}
\hline & $\frac{\text { No of }}{\text { responses }}$ & $<20 \%$ & $21-40 \%$ & $41-60 \%$ & $61-80 \%$ & $81-100 \%$ \\
\hline Medication Dispensing & $40(7.2)$ & $48(8.7)$ & $539.6)$ & $109(19.7)$ & 105(19.0) & $199(35.9)$ \\
\hline Consultation & $41(7.4)$ & $177(31.9)$ & $88(15.9)$ & $55(9.9)$ & $98(17.7)$ & $95(17.1)$ \\
\hline Drug Use Management & $75(13.5)$ & $177(31.9)$ & $45(8.1)$ & $58(10.5)$ & $76(13.7)$ & $122(22.0)$ \\
\hline Pharmaceutical care & $118(21.3)$ & $164(29.6)$ & $56(10.1)$ & $54(9.7)$ & $86(15.5)$ & $76(13.7)$ \\
\hline $\begin{array}{l}\text { Clinical pharmacist } \\
\text { services }\end{array}$ & $261(47.1)$ & $106(19.1)$ & $33(6.0)$ & $68(12.3)$ & $34(6.1)$ & $52(9.4)$ \\
\hline Disease management & $244(44.0)$ & $125(22.6)$ & $47(8.5)$ & $57(10.3)$ & $53(9.6)$ & $28(5.1)$ \\
\hline Business Management & $182(32.9)$ & $136(24.5)$ & $52(9.4)$ & $54(9.7)$ & $6.1(11.0)$ & $69(12.5)$ \\
\hline Marketing & $176(31.8)$ & $117(21.1)$ & $55(9.9)$ & $74(13.4)$ & $69(12.5)$ & $63(11.4)$ \\
\hline Education & $163(29.4)$ & $126(22.7)$ & $48(8.7)$ & $58(10.5)$ & $82(14.8)$ & $77(13.9)$ \\
\hline
\end{tabular}


the region $(p<0.001)$ and the monthly income $(p<0.001)$. Thus, the LSD results for the region variable were examined to show the direction of the differences, showing that the differences were in favor of the middle region and for incomes greater than 6,000 NIS. However, for the domain of leaving work with a good feeling, the results show that for gender the differences is in favor of females $(p<0.001)$, for practical settings variable, pharmacy hospital was favored $(p<0.001)$ and for position variable in favor of pharmacy owner $(p<0.001)$.

\section{Job stress}

Table 4 represents the stress domains, which consist of 30 items.

Table 4. The means and standard deviations of scores for domains of health professions stress inventory (HPSI)

\begin{tabular}{cccccc}
\hline$\#$ & Domain & $\begin{array}{c}\text { No. of } \\
\text { Items }\end{array}$ & $\begin{array}{c}\text { Possible range } \\
\text { of scores }\end{array}$ & $\mathrm{M}$ & SD \\
\hline 1 & Patient care & 8 & $1-5$ & 3.13 & 0.650 \\
2 & $\begin{array}{l}\text { Professional } \\
\text { recognition }\end{array}$ & 7 & $1-5$ & 2.77 & 0.623 \\
3 Job conflicts & 7 & $1-5$ & 2.47 & 0.606 \\
4 & $\begin{array}{l}\text { Professional } \\
\text { uncertainty }\end{array}$ & 8 & $1-5$ & 2.31 & 0.640 \\
$\quad$\begin{tabular}{l} 
Total \\
\hline
\end{tabular} & 30 & $1-5$ & 2.61 & 0.485 \\
\hline
\end{tabular}

The responses ranged from 1 , which was for never stressed, to 5 , which was for frequently stressed. The overall mean of the stress scores was 2.61 and the standard deviation was 0.485 , which indicated that the level of work stress of the pharmacists was medium. Patient Care has the highest average score $(3.13 \pm 0.65)$ and the lowest was the Professional uncertainty score $(2.31 \pm 0.48)$. The four job situations that the pharmacists perceived as the most stressful were as follows: "Trying to meet society's expectations for high-quality medical care" in the patient care domain(3.54 1.01); "Having job duties which conflict with family responsibilities" in the job conflict domain

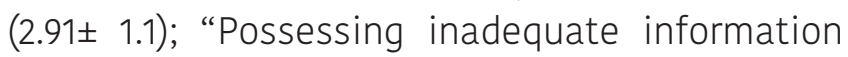

regarding a patient's medical condition" in the profession uncertainty domain (2.57 \pm 1.04$)$; and "Feeling that opportunities for advancement on the job are poor" in the profession recognition domain (3.3 1.1 ). Community pharmacists feel stress regarding responsibility for patient outcomes and phone call interruptions, while hospital pharmacists feeling stress when they debate with supervisors and or administrators when they have too much work to do.

Table 5 shows the t-tests and ANOVA analyses revealed that hospital pharmacists were the least likely to respond that job conflicts with family responsibility as a source of stress compared with community pharmacists (3.11 vs $2.14 ; p<0.001$ ) and least likely scores in the professional recognition domain (3.21 vs. 2.79; $p$ $=0.04$ ), respectively. A higher mean stress score was reported by newly practicing (i.e. less than 3 years) community pharmacists compared with pharmacists who were practicing $>3$ years, with regard to the domains of patient care responsibility (3.41 vs. 2.11, $p<0.001$ ) and professional uncertainty (2.78 vs. 2.14, $p=0.005$ ). The top situation that new pharmacists considered to be the most stressful was "Fearing that a mistake will be made in the treatment of a patient."

\section{Physician Cooperation}

Thirty five percent (35\%) of the respondents to this question indicated that there is a very good professional relationship between the doctor and pharmacist, on the other hand $45 \%$ of the respondents indicated that physicians cooperation with pharmacist is not enough or rare. In general, some physicians are highly cooperative while others cling on to their opinion even if they are wrong.

sick leave

It is a difficult situation when pharmacists ask for casual or sick leaves, because it is a struggle to find a replacement, and $30 \%$ of the respondents answered that there was no available paid sick leave for them, $40 \%$ of the respondents indicated that it was not enough for them, and the rest said it was there when necessary. 
Table 5. The means, standard deviations, and level of significant of the responses of the study sample members to level of work stress of participant pharmacists

\begin{tabular}{|c|c|c|c|c|c|c|c|c|c|c|c|c|c|c|c|c|}
\hline \multirow[b]{2}{*}{ Variable } & \multirow[b]{2}{*}{$\mathrm{N}$} & \multicolumn{3}{|c|}{ Patient care } & \multicolumn{3}{|c|}{ Professional recognition } & \multicolumn{3}{|c|}{ Job conflicts } & \multicolumn{3}{|c|}{ Professional uncertainty } & \multicolumn{3}{|c|}{ Total } \\
\hline & & M & SD & Sig. & M & SD & Sig. & M & SD & Sig. & M & SD & Sig. & M & SD & Sig. \\
\hline \multicolumn{17}{|l|}{ Region } \\
\hline North & 281 & 2.57 & 0.647 & 0.812 & 3.11 & 0.662 & 0.128 & 2.46 & 0.635 & 0.407 & 2.32 & 0.649 & 0.481 & 2.60 & 0.511 & 0.427 \\
\hline South & 115 & 2.57 & 0.584 & & 3.24 & 0.638 & & 2.54 & 0.545 & & 2.35 & 0.596 & & 2.66 & 0.435 & \\
\hline Middle & 158 & 2.60 & 0.609 & & 3.10 & 0.633 & & 2.45 & 0.595 & & 2.26 & 0.654 & & 2.59 & 0.473 & \\
\hline \multicolumn{17}{|l|}{ Gender } \\
\hline Male & 231 & 2.55 & 0.615 & 0.332 & 3.13 & 0.663 & 0.921 & 2.51 & 0.597 & 0.189 & 2.27 & 0.661 & 0.319 & 2.61 & 0.480 & 0.892 \\
\hline Female & 323 & 2.60 & 0.628 & & 3.14 & 0.643 & & 2.44 & 0.612 & & 2.33 & 0.624 & & 2.62 & 0.489 & \\
\hline \multicolumn{17}{|l|}{$\begin{array}{l}\text { Academic } \\
\text { Degree }\end{array}$} \\
\hline B. Sc. & 453 & 2.55 & 0.617 & 0.054 & 3.11 & 0.662 & 0.176 & 2.47 & 0.606 & $0.015^{*}$ & 2.29 & 0.632 & 0.363 & 2.60 & 0.488 & $0.043^{*}$ \\
\hline $\begin{array}{l}\text { Pharm. D } \\
\text { Post Bach. }\end{array}$ & 61 & 2.62 & 0.607 & & 3.20 & 0.499 & & 2.37 & 0.558 & & 2.38 & 0.658 & & 2.62 & 0.411 & \\
\hline Pharm. D & 40 & 2.79 & 0.684 & & 3.30 & 0.707 & & 2.72 & 0.632 & & 2.40 & 0.697 & & 2.80 & 0.524 & \\
\hline \multicolumn{17}{|l|}{$\begin{array}{l}\text { Practical } \\
\text { Setting } \\
\text { Community }\end{array}$} \\
\hline Pharmacy & 408 & 2.62 & 0.603 & 0.251 & 3.21 & 0.592 & $0.046^{*}$ & 3.11 & 0.571 & $0.001^{*}$ & 2.35 & 0.624 & 0.125 & 2.65 & 0.436 & 0.087 \\
\hline $\begin{array}{l}\text { Hospital } \\
\text { Pharmaceutical }\end{array}$ & 79 & 2.57 & 0.668 & & 2.79 & 0.748 & & 2.14 & 0.639 & & 2.18 & 0.587 & & 2.54 & 0.538 & \\
\hline $\begin{array}{l}\text { Company } \\
\text { Medical }\end{array}$ & 37 & 2.65 & 0.465 & & 2.90 & 0.744 & & 2.71 & 0.560 & & 2.29 & 0.605 & & 2.64 & 0.475 & \\
\hline Representative & 30 & 2.85 & 0.913 & & 3.07 & 0.440 & & 2.98 & 0.570 & & 2.67 & 0.669 & & 2.90 & 0.500 & \\
\hline \multicolumn{17}{|l|}{ Position } \\
\hline $\begin{array}{l}\text { Owner of the } \\
\text { pharmacy }\end{array}$ & 172 & 2.51 & 0.556 & 0.246 & 3.17 & 0.570 & 0.170 & 2.44 & 0.570 & 0.154 & 2.25 & 0.605 & 0.359 & 2.58 & 0.433 & 0.622 \\
\hline employee & 382 & 2.60 & 0.646 & & 3.13 & 0.679 & & 2.48 & 0.609 & & 2.33 & 0.655 & & 2.62 & 0.500 & \\
\hline \multicolumn{17}{|l|}{ Experience } \\
\hline$<$ a year & 114 & 3.41 & 0.611 & $0.001^{*}$ & 3.27 & 0.631 & $0.058^{*}$ & 2.47 & 0.669 & 0.324 & 2.78 & 0.630 & $0.005^{*}$ & 2.69 & 0.515 & $0.008^{*}$ \\
\hline $1-3$ & 165 & 3.12 & 0.643 & & 3.16 & 0.550 & & 2.50 & 0.554 & & 2.35 & 0.636 & & 2.65 & 0.424 & \\
\hline $4-6$ & 91 & 2.63 & 0.628 & & 3.01 & 0.723 & & 2.51 & 0.586 & & 2.31 & 0.655 & & 2.61 & 0.518 & \\
\hline $7-10$ & 51 & 2.11 & 0.500 & & 3.15 & 0.565 & & 2.56 & 0.580 & & 2.27 & 0.560 & & 2.65 & 0.383 & \\
\hline$>10$ years & 133 & 2.38 & 0.613 & & 3.06 & 0.738 & & 2.38 & 0.633 & & 2.14 & 0.644 & & 2.49 & 0.521 & \\
\hline \multicolumn{17}{|l|}{ Monthly income } \\
\hline$<1000$ NIS & 9 & 2.65 & 0.328 & 0.066 & 3.52 & 0.446 & 0.388 & 2.52 & 0.458 & 0.456 & 2.43 & 0.343 & 0.056 & 2.76 & 0.249 & 0.275 \\
\hline $1000-2000$ & 171 & 2.64 & 0.675 & & 3.17 & 0.645 & & 2.43 & 0.623 & & 2.36 & 0.648 & & 2.64 & 0.519 & \\
\hline $2001-3000$ & 158 & 2.62 & 0.624 & & 3.11 & 0.681 & & 2.47 & 0.624 & & 2.33 & 0.685 & & 2.62 & 0.516 & \\
\hline $3001-4000$ & 87 & 2.50 & 0.627 & & 3.05 & 0.705 & & 2.58 & 0.608 & & 2.25 & 0.641 & & 2.59 & 0.475 & \\
\hline 49001-5000 & 51 & 2.34 & 0.550 & & 3.11 & 0.614 & & 2.39 & 0.579 & & 2.04 & 0.549 & & 2.47 & 0.404 & \\
\hline $5001-6000$ & 36 & 2.57 & 0.555 & & 3.09 & 0.485 & & 2.43 & 0.591 & & 2.25 & 0.519 & & 2.57 & 0.413 & \\
\hline$>6000 \mathrm{NIS}$ & 42 & 2.59 & 0.515 & & 3.23 & 0.630 & & 2.57 & 0.527 & & 2.42 & 0.609 & & 2.69 & 0.410 & \\
\hline \multicolumn{17}{|l|}{ Job Status } \\
\hline Full time job & 357 & 2.54 & 0.601 & $0.036^{*}$ & 3.10 & 0.649 & 0.125 & 2.50 & 0.598 & 0.359 & 2.30 & 0.633 & 0.752 & 2.60 & 0.469 & 0.388 \\
\hline Part time job & 167 & 2.68 & 0.624 & & 3.22 & 0.626 & & 2.44 & 0.608 & & 2.33 & 0.636 & & 2.65 & 0.490 & \\
\hline
\end{tabular}




\section{Paid overtime}

Inadequate pay and few opportunities for job advancement were often being one of the stress sources among pharmacist. Most of the answers concentrated that sometimes there are extra working hours but without pay, or do not count any extra hour as overtime.

\section{Discussion}

Until now, the degree of stress and job satisfaction among Palestinian pharmacists has not been studied. Generally, results indicate medium scores of job satisfaction among Palestinian pharmacists; most are satisfied with being pharmacist and are satisfied with their present job compared to others. The pharmacists questioned in the present study presented a greater degree of job satisfaction in comparison to other studies. For example, $57 \%$ of community pharmacists in the UK were reported to be content with their current job "most of the time" (McCann, Hughes et al. 2009), and in other study, $38 \%$ of Jordanian pharmacists reported that they were satisfied with their job (Al Khalidi and Wazaify 2013). Moderate levels of job dissatisfaction were found for community and clinical pharmacists, while clinical pharmacists reported higher level of stress than community pharmacists. These findings are consistent with previous research (Maio, Goldfarb et al. 2004, Hassell 2006, Liu and White 2011, Munger, Gordon et al. 2013, Johnson, O'connor et al. 2014). Although dispensing is an essential component in the delivery of any pharmaceutical service, community pharmacists often feel unappreciated and get a sense that their abilities are not being employed in the patient care process. For example, a study in Arizona revealed that job satisfaction was significantly correlated with the apparent application of their skills amid community and hospital pharmacists(Cox and Fitzpatrick 1999). Our study also revealed that numerous controlling factors played a statistically significant role in influencing a pharmacist's job satisfaction and intentions to leave their job; these included the pharmacist's education level, gender, and monthly income. For example, male pharmacists were more likely to have intentions to leave their job compared to female pharmacists. The reason for this may be that female pharmacists are typically more stable in their respective position, while male pharmacists are more willing to seek out higher paying jobs in other pharmaceutical sectors, such as pharmaceutical sales(Lin, Yeh et al. 2007, Seston, Hassell et al. 2009, Majd, Hashemian et al. 2012). The findings showed that job satisfaction was not statistically different among Palestinian pharmacists based on whether the pharmacists owned the pharmacy or not. The only exception was regarding the question of "leaving work with a "bad" feeling", and the results indicated a higher job satisfaction among the owners. This could be explained by the fact that salary increases with pharmacy ownership; this may explain the higher job satisfaction for the pharmacy owner and pharmacists with high monthly wage of more than 6000NIS(Salameh and Hamdan 2007). Job satisfaction among Palestinian pharmacists due to the years of experience was not significantly different. Our results contradict other studies, which indicate that pharmacists with more years of experience have a greater sense of job satisfaction.

With regard to stress, in the present study, the level of perceived stress was higher (an overall mean of 2.61) than the overall mean stress reported in Northern Ireland study (McCann, Hughes et al. 2009). Furthermore, the level reported in our study was also greater than the Swedish normative data, which derived from 3406 individuals, showing a mean perceived stress scale score of 13.96 (Nordin and Nordin 2013). "Feeling that opportunities for advancement on the job are poor" was a major cause of the stress reported by pharmacists as was not obtaining prospects for improvement. In addition, "Not having opportunities to share feelings and experiences with colleagues" and "Not being able to use your abilities to the fullest extent on the job" were important concerns for a 
great number of pharmacists. On the other hand, as mentioned by Doody (Doody 2012), "Not being recognized as a true health professional by other health professionals" was one of the main causes of stress for pharmacists, in addition to not being acknowledged by the general public. The most common cause of stress among the respondents was "possessing inadequate information regarding a patient's medical condition."

It is possible that this was related to the high level of accountability that they have. On the other hand, as mentioned in previous publications (Doody 2012), the most common cause of stress is reported to be related to "having to balance new roles with existing responsibilities." The reason for this stress area, might be due to increased pharmacy regulations, which equates to an increased level of responsibility. Moreover, community pharmacists' stress may be related to the fact that pharmacist play a dual role, on the one hand there is a business component to the profession in addition to being a health care professional(Bond, Matheson et al. 2000, Resnik, Ranelli et al. 2000, Austin, Gregory et al. 2010). There is a common expectation for community pharmacists to provide patient pharmaceutical care in spite of inadequate information available about patient condition. This stressful situation causes the pharmacist to feel uncertain of how to counsel the patient (Resnik, Ranelli et al. 2000). The main cause of stress for clinical or hospital pharmacists appears to be due to daily job conflicts with other health care professionals. Participation of clinical pharmacists in Palestinian hospitals is relatively new (Mukattash, Hayajneh et al. 2016, Khdour, Hallak et al. 2018), as such they may not be accepted by physicians and other health care professionals that may not acknowledge the newer clinical services delivered through the pharmacist (Tahaineh, Wazaify et al. 2009). Similarly, a study in Riyadh found jobrelated stress factors, such as the setting of the pharmacy and years of experience, had a significant effect on the stress level related to the responsibility of patient care (Slimane 2017). A possible explanation for this is that pharmacists, whether they work in a chain pharmacy or work an independent community pharmacy, feel that their professional training is not utilized as much as their fellow health care professionals, and this would include patient-oriented functions, such as clinical-related activities and direct patient care. Generally, dispensing pharmacists might not feel appreciated, such that the skills they obtained in their training are not being fully utilized for patient care. Based on the free text analysis, in which the respondents were permitting to express any other issues or concern, we found that for the community pharmacists, it was difficult to establish a relationship with the physicians, and $45 \%$ of the respondents responded that the physicians rarely cooperated with the and that whatever cooperation they received was not enough. Any cooperation usually rely on the physician personality, some physicians are cooperative while other clings to their opinion even if they are wrong. For example, new doctors in all specialties are more likely to interact with pharmacist than older doctors, and some may ask pharmacists to recommend the best drug choice (Allenet and Barry 2003). On the other hand, many pharmacists described that physicians will regularly refuse their suggestions for replacing unavailable drugs brands with available substitutes. Another challenge that pharmacists face is that it is difficult to ask for time off using casual or sick leave, because it is not easy to find a replacement. As such, 30\% of the respondents answered that there was no available paid sick leave for them, and $40 \%$ of the respondents complained that they do not get enough time to rest when necessary. The pharmacists also reported that the interaction between physicians and pharmaceutical companies, which may lead to inappropriate prescribing, was also a source of stress and dissatisfaction. This finding is consistent with reports demonstrating that when drug samples are available physicians were likely to be influenced to prescribe a drug that is different from their preferred drug of choice. 
Thus, evidence-based guideline compliance may be compromised (Chew, O’Young et al. 2000).

\section{Study Limitations}

Satisfaction and stress are topics that remain controversial and still have potential for producing bias. Therefore, caution should be considered when interpreting the results of this study. Furthermore, there may have been errors by the pharmacists in recollecting some information. However, in an effort to minimize these errors, at any given opportunity, the researcher made sure that the participants were fully aware of the fact that they were able to reach out to the researcher by phone or email for any extra clarification. The personal social, emotional and financial status of the pharmacists may affect the results. However, we did not examine these factors in detail in this study.

\section{Conclusion}

This study revealed that the participating pharmacists experienced moderate levels of jobrelated stress and dissatisfaction. Community pharmacists described less satisfaction compared to pharmacists working in a hospital setting. The study results suggested that ample attention must be given to the demands placed on pharmacists on the job and their interactions with healthcare professionals in order to improve the work life quality of the pharmacist. Policy makers must pay special attention to raise the levels of job satisfaction for pharmacists in order to improve their motivation and ability, because failure to reduce stress among workers puts both pharmacists and patients at risk.

\section{Acknowledgement}

We thank the pharmacists who participated in the study and the Palestinian pharmaceutical association who facilitated the study.

\section{Funding}

This research was not supported by any specific grant from funding agencies in the public, commercial, or not-for-profit sectors.

\section{Availability of data and materials}

The raw dataset may be provided by the corresponding author upon reasonable request.

\section{Authors' contributions}

MK was conceived the idea for the study, led study design. JS collected the data, entered the data into SPSS, and conducted the data analysis. $\mathrm{HH}$ interpreted the data, and drafting of manuscript; All authors read and approved the final manuscript and agreed on its submission.

\section{Ethics approval and consent to participate}

The study was approved and authorized by the Institutional research ethics committee (REC) of Al-Quds University (39/REC/2018). Verbal consent was also obtained from the participant pharmacists prior to the commencement of the study.

\section{Consent for publications}

N/A

\section{Competing interest}

The authors declare that they have no competing interest.

\section{References}

Al Khalidi, D. and M. Wazaify (2013). "Assessment of pharmacists' job satisfaction and job related stress in Amman." International journal of clinical pharmacy 35(5): 821-828.

Allenet, B. and H. Barry (2003). "Opinion and behaviour of pharmacists towards the substitution of branded drugs by generic drugs: survey of 1,000 French community pharmacists." Pharmacy World and Science 25(5): 197-202.

Austin, Z., P. A. Gregory and J. C. Martin (2010). "Pharmacists' experience of conflict in community practice." Research in social and administrative pharmacy 6(1): 39-48.

Baloch, Q. B. (2009). "Effects of job satisfaction on employees motivation \& turn over intentions." Journal of Managerial Sciences 2(1): 1-21.

Bond, C., C. Matheson, S. Williams, P. Williams and P. Donnan (2000). "Repeat prescribing: a role 
for community pharmacists in controlling and monitoring repeat prescriptions." $\mathrm{Br} J$ Gen Pract 50(453): 271-275.

Chew, L. D., T. S. O’Young, T. K. Hazlet, K. A. Radley, C. Maynard and D. S. Lessler (2000). "A physician survey of the effect of drug sample availability on physicians' behavior." Journal of General Internal Medicine 15(7): 478-483.

Cox, E. R. and V. Fitzpatrick (1999). "Pharmacists' job satisfaction and perceived utilization of skills." American journal of health-system pharmacy 56(17): 1733-1737.

Desselle, S. P. and G. L. Peirce (2011). "The intersection of job satisfaction and preceptor development: opportunities for academic pharmacy programs." American journal of pharmaceutical education 75(9).

Doody, T. M. (2012). An explorative study into workrelated stress among Community Pharmacists in Ireland, Dublin, National College of Ireland.

Edwards, D. and P. Burnard (2003). "A systematic review of stress and stress management interventions for mental health nurses." Journal of advanced nursing 42(2): 169-200.

Faragher, E. B., M. Cass and C. L. Cooper (2013). The relationship between job satisfaction and health: a meta-analysis. From Stress to Wellbeing Volume 1, Springer: 254-271.

Felton, J. S. (1998). "Burnout as a clinical entity-its importance in health care workers." Occupational medicine 48(4): 237-250.

Ferguson, J., D. Ashcroft and K. Hassell (2011). "Qualitative insights into job satisfaction and dissatisfaction with management among community and hospital pharmacists." Research in Social and Administrative Pharmacy 7(3): 306316.

Hassell, K. (2006). "Destination, future intentions and views on practice of British-based pharmacists 5 and 10 years after qualifying." Pharmacy World and Science 28(3): 116.

Herzog, A. (2000). "Conflict resolution in a nutshell: tips for everyday nursing." SCI nursing: a publication of the American Association of Spinal Cord Injury Nurses 17(4): 162-166.

Johnson, S., E. O'connor, S. Jacobs, K. Hassell and D. Ashcroft (2014). "The relationships among work stress, strain and self-reported errors in UK community pharmacy." Research in social and administrative pharmacy 10(6): 885-895.

Kälvemark, S., A. T. Höglund, M. G. Hansson, P. Westerholm and B. Arnetz (2004). "Living with conflicts-ethical dilemmas and moral distress in the health care system." Social science \& medicine 58(6): 1075-1084.

Keil, R. M. (2004). "Coping and stress: a conceptual analysis." Journal of advanced nursing 45(6): 659665.

Khdour, M. R., H. O. Hallak, M. A. Aldeyab, M. A. Nasif, A. M. Khalili, A. A. Dallashi, M. B. Khofash and M. G. Scott (2018). "Impact of antimicrobial stewardship programme on hospitalized patients at the intensive care unit: a prospective audit and feedback study." British journal of clinical pharmacology 84(4): 708-715.

Kreling, D. H., W. R. Doucette, D. A. Mott, C. A. Gaither, C. A. Pedersen and J. C. Schommer (2006). "Community pharmacists' work environments: evidence from the 2004 National Pharmacist Workforce Study." Journal of the American Pharmacists Association 46(3): 331-339.

Lin, B. Y.-J., Y.-C. Yeh and W.-H. Lin (2007). "The influence of job characteristics on job outcomes of pharmacists in hospital, clinic, and community pharmacies." Journal of medical systems 31(3): 224-229.

Liu, C. S. and L. White (2011). "Key determinants of hospital pharmacy staff's job satisfaction." Research in Social and Administrative Pharmacy 7(1): 51-63.

Maio, V., N. I. Goldfarb and C. W. Hartmann (2004). "Pharmacists' job satisfaction: variation by practice setting."

Majd, M., F. Hashemian, F. Y. Sisi, M. Jalal and Z. Majd (2012). "Quality of life and job satisfaction of dispensing pharmacists practicing in Tehran private-sector pharmacies." Iranian journal of pharmaceutical research: IJPR 11(4): 1039.

McCann, L., C. M. Hughes, C. G. Adair and C. Cardwell (2009). "Assessing job satisfaction and stress among pharmacists in Northern Ireland." Pharmacy world \& science 31(2): 188.

McNeely, E. (2005). "The consequences of job stress for nurses' health: time for a check-up." Nursing outlook 53(6): 291-299.

Merrick, J. (2000). Firth-Cozens J, Payne R, eds. Stress in health professionals. Psychological and organizational causes and interventions. Chichester, England: John Wiley, 1999, 264 pages, $\mathrm{E} 17.99$.

Mott, D. A., W. R. Doucette, C. A. Gaither, C. A. Pedersen and J. C. Schommer (2004). "Pharmacists' attitudes toward worklife: results from a national survey of pharmacists." Journal of the American Pharmacists Association 44(3): 326-336.

Mukattash, T. L., K. H. Alzoubi, E. Abu El-Rub, A. S. Jarab, S. I. Al-Azzam, M. Khdour, M. Shara and 
Y. N. Al Hamarneh (2016). "Prevalence of nonadherence among psychiatric patients in Jordan, a cross sectional study." International Journal of Pharmacy Practice 24(3): 217-221.

Mukattash, T. L., W. A. Hayajneh, S. M. Ibrahim, A. Ayoub, N. Ayoub, A. S. Jarab, M. Khdour and A. Almaaytah (2016). "Prevalence and nature of off-label antibiotic prescribing for children in a tertiary setting: A descriptive study from Jordan." Pharmacy Practice (Granada) 14(3): 0-0.

Munger, M. A., E. Gordon, J. Hartman, K. Vincent and M. Feehan (2013). "Community pharmacists" occupational satisfaction and stress: a profession in jeopardy?" Journal of the American Pharmacists Association 53(3): 282-296.

Nordin, M. and S. Nordin (2013). "Psychometric evaluation and normative data of the Swedish version of the 10 item perceived stress scale." Scandinavian journal of psychology 54(6): 502507.

Resnik, D. B., P. L. Ranelli and S. P. Resnik (2000). "The conflict between ethics and business in community pharmacy: what about patient counseling?" Journal of Business Ethics 28(2): 179-186.

Saari, L. M. and T. A. Judge (2004). "Employee attitudes and job satisfaction." Human Resource Management: Published in Cooperation with the School of Business Administration, The University of Michigan and in alliance with the Society of Human Resources Management 43(4): 395-407.

Salameh, P. and I. Hamdan (2007). "Pharmacy manpower in Lebanon: An exploratory look at workrelated satisfaction." Research in Social and Administrative Pharmacy 3(3): 336-350.
Sansgiry, S. S. and C. Ngo (2003). "Factors affecting job satisfaction among hospital pharmacists." Hospital Pharmacy 38(11): 1037-1046.

Seston, E., K. Hassell, J. Ferguson and M. Hann (2009). "Exploring the relationship between pharmacists' job satisfaction, intention to quit the profession, and actual quitting." Research in Social and Administrative pharmacy 5(2): 121-132.

Slimane, N. S. B. (2017). "Motivation and job satisfaction of pharmacists in four hospitals in Saudi Arabia." Journal of Health Management 19(1): 39-72.

Smith, W. E., M. D. Ray and D. M. Shannon (2002). "Physicians' expectations of pharmacists." American journal of health-system pharmacy 59(1): 50-57.

Snyder, M. E., A. J. Zillich, B. A. Primack, K. R. Rice, M. A. S. McGivney, J. L. Pringle and R. B. Smith (2010). "Exploring successful community pharmacistphysician collaborative working relationships using mixed methods." Research in social and administrative pharmacy 6(4): 307-323.

Stafford-Brown, J. and K. I. Pakenham (2012). "The effectiveness of an ACT informed intervention for managing stress and improving therapist qualities in clinical psychology trainees." Journal of clinical psychology 68(6): 592-513.

Tahaineh, L. M., M. Wazaify, A. Albsoul-Younes, Y. Khader and M. Zaidan (2009). "Perceptions, experiences, and expectations of physicians in hospital settings in Jordan regarding the role of the pharmacist." Research in social and administrative pharmacy 5(1): 63-70.

Wolfgang, A. P. (1988). "The health professions stress inventory." Psychological Reports 62(1): 220-222. 